velocity at $F$, (thirty-one inches lower down in the water) in the proportion of $18 \frac{1}{2}$ to $12 \frac{1}{2}$.

It would be interesting to repeat the experiment under different circumstances; for example, in currents of two, and in currents of six, or more miles per hour; in rivers of three, and in rivers of ten, or more feet in depth, and with the lower fan (as F) as near as could be to the bottom.

The reason of the current of rivers or streams being greatest at the sur. face, and diminishing gradually to the bottom, seems to be manifest. It is on the principle of bodies falling or sliding down inclined planes. The application of the principle is more obscure and difficult in the case of the river, on account of the falling or sliding body being a liquid, instead of a solid body.

It is on the same principle that the velocity of the current of a river in. creases, in proportion as it is swelled and raised higher and higher by rains and Hoods.

\title{
On the Velocity of Floating Bodies along the Current of a River.
}

When I lived in Harrisburg, $I$ often heard raftmen and boatmen say that rafts, loaded boats, and arks, floated faster than the current of the Susquehanna. They said that when a rise occurred in the river, in consequence of a heavy rain above any particular point, say Sunbury or Wilkesbarre, if a boat or raft started with the flood, it would soon go beyond the flood, and get into shallow water, and that, for this reason, it was their practice never to start till the rise, or flood, had preceded them about twenty-four hours.

They also said that a heavy boat, or raft, floated faster than a light one, and that, by fastening two or more rafts together, their speed was increased.

The facts seemed probable, independent of the direct testimony of the boatmen, and to be accounted for on the principle of falling bodies, and bodies sliding down inclined planes, acquiring velocity in their progress, the acquisition of velocity being in proportion to the inclination of the plane, and the weight of the descending body.

To ascertain the fact that a loaded boat floated faster than the current, the following experiment was made in the summer of 1811, by sereral scientific gentlemen, with myself.

A common water wheel was made, about sixteen inches in diameter, and fastened to the end of a stick, or shaft, about two feet in length. We entered a skiff, and went to a rapid part of the river, where the current, for the distance below us of one hundred yards and upwards, was even, and of the rapidity, as we estimated it, of five miles per hour. The skiff was anchored; I sat in the middle of it, hanging the water wheel over the side of the skiff, so that the wheel dipped an inch, or more, in the water. The shaft rested on the side of the skiff, and I held it loosely in my hands, allowing it to turn round freely, as the current gave motion to the wheel.

While the skiff remained at anchor, the force of the current made the wheel turn pretty quickly upwards, or against the stream. The rope that held the skiff to the stone that served for an anchor was cut, and the skiff was allowed to float down the river. The skiff gradually but rapidly increased in the velocity of its motion, and the motion of the water wheel turning upwards, or against the current, proportionably diminished in velocity. After the skiff had floated not more (as well as I can remember at 
this time) than four or five rods, the motion of the wheel on its axis, or shaft, ceased altogether, and it began to turn on its axis down the stream, slowly at firet, but quickly increasing. And alter the skiff had toated not more (I think) than fourtcen or fifteen rods from the place where it had been anchored, the water wheel turned downwards, or with the current, as often as once round in the distance of a rod, or less.

It is evident that while the wheel turned up the stream, the current of the river went faster than the skiff, or ran past it; and when the wheel turned down the stream, the motion of the skiff was more rapid than that of the current. We expected this result in a certain degree, but all of us were surpries that the floating skiff should so soon acquire a velocity greater than that of the current of the river.

It would be interesting to repeat this experiment under change of circum. stances. For instance :

1. In a slower, and in a more rapid, current.

2. In a boat heavily, and one lightly, loaded.

3. In a flat bottomed, and in a sharp keeled, boat.

4. On rafts of different sizes.

Also, to ascertain whether any difference would arise from laving the load lie in the hottom of the boat, such as a quantity of pig metal, or having the load consist of men standing up in the boat.

'Iimes and dislances should, of course, be accurately noted.

E.

\section{Listimale of the Water discharged by a River.}

If the currents of rivers diminish from the surface towards the bottom, and be very slow at the bottom, the quantity of water discbarged by rivers into the ocean is much less than has becn usually imagined. Dr. Halley, in his theory of the origin of springs, probably estimates much too largely the quantity of water poured into the ocean by all the rivers of the world.

When the dam at Fairmount, near Philadelphia, was crected across the Schuylkill, it was stated, in some of the newspapers, that some gentlemen wished to ascertain the quantity of water that flowed in the river in a given timc. For this purpose, the newspapers said that the breadth and depth of the river at Fairmount were measured, and that to obtain the velocity of the motion of the water in the river, four or five gentlemen entered a boat, and floated a certain distance on the river, noting the time required to pass a given distance, after the boat had acquired its natural velocity and motion, as it was called.

If the newspaper account was correct, it would seem that two great errors entered into the calculation.

First. The current diminished in velocity from the surface to the bottom, the current in the bottom of rivers being very slight, unless in places where the descent in the bottom, or bed, is considerable, as at rapids or ripples.

Second. The boat loaded with four or five men floated much faster than the fastest part of the current of the river, faster than the current at the surface.

E.

\section{Franklin Institute.}

Annual Mceting.

The Annual Meeting of the Institute was held at their Hall, on Thursday evening, Jau. 19th, 1837, 